\title{
Chlamydial and gonococcal antibodies in sera of infertile women with tubal obstruction
}

\author{
J N ROBERTSON,* M E WARD,* D CONWAY, $\dagger$ E O CAUL \\ From the ${ }^{*}$ Faculty of Medicine, Southampton General Hospital, Southampton; the $†$ Bellshill Maternity \\ Hospital, Bellshill, Lanarkshire; and the $\ddagger$ Public Health Laboratory, Kingsdown, Bristol
}

SUMMARY Sera from 48 infertile women with tubal pathology and from 77 infertile women with normal fallopian tubes were tested by enzyme linked immunosorbent assay (ELISA) using Chlamydia trachomatis and Neisseria gonorrhoeae antigens. Control sera were obtained from women undergoing abortion, sterilisation, and from women practising barrier contraception. The results of ELISA for antibodies to chlamydiae were in close agreement with results published previously of an immunofluorescence test on these sera. ${ }^{8}$ Antibodies to C trachomatis were found in $73 \%$ of the infertile women with tubal pathology, significantly more than in any of the control groups. Only a very low prevalence $(2-5 \%)$ of antibodies to gonococcal pili was found in all groups, except women undergoing abortion (16\%).

Several studies have established the importance of Chlamydia trachomatis in the aetiology of infertility due to tubal occlusion following salpingitis. ${ }^{12}$ The relative importance of Neisseria gonorrhoeae as opposed to $C$ trachomatis in this process has been less extensively investigated, particularly in the United Kingdom. Studies in southern Sweden and France indicate that gonococci or mycoplasma are a less common cause of salpingitis, and by implication, of infertility, than are chlamydiae. ${ }^{34}$ In Holland, however, a serological study suggested that gonococci were a more common cause of infertility with tubal dysfunction than were chlamydiae. ${ }^{5}$ In The Gambia in West Africa both gonococci and $C$ trachomatis are highly prevalent in sexually active urban populations, ${ }^{6}$ and serological studies indicate that these organisms are of similar importance in the aetiology of infertility following tubal occlusion. ${ }^{7}$

Conway et $a l^{8}{ }^{8}$ using a whole inclusion immunofluorescence test (WIF), ${ }^{9}$ showed circulating antibodies to C trachomatis in 36 of 48 infertile women with damaged tubes, 23 of 75 infertile women with normal tubes, and 17 of 72 normal women using barrier contraception in Bristol. The present paper describes the results of a collaborative study performed on these Bristol sera with two main objectives.

Accepted for publication 9 October 1986
Firstly, to determine the importance of gonococci in the aetiology of tubal infertility in the United Kingdom by measuring the prevalence of gonococcal antibody, and secondly, to determine in two independent laboratories the comparative merits of enzyme linked immunosorbent assay (ELISA) and WIF as screening procedures for the serological identification of past or present chlamydial infection.

\section{Patients and methods}

Blood samples were collected from 48 infertile patients with tubal pathology and from 77 infertile patients with normal fallopian tubes (table 1). Primary infertility was defined as failure to conceive at any time, while secondary infertility meant that the patient had been pregnant. Tubal condition was assessed by laparoscopy, hysterosalpingography, or both. Additional control sera were obtained from

Table 1 Gynaecological history of infertile patients studied

\begin{tabular}{lll}
\hline & \multicolumn{2}{l}{ Infertility with: } \\
\cline { 2 - 3 } & Tubal pathology & Normal tubes \\
\hline No of patients & 48 & 77 \\
Mean age (years) & 28.9 & $29 \cdot 2$ \\
Age range (SD) & $19-42(4 \cdot 83)$ & $19-41(3 \cdot 96)$ \\
No using coil (\%)* & $5 / 43(11 \cdot 6)$ & $8 / 71(11 \cdot 3)$ \\
No with history of PID (\%)* & $13 / 42(31)$ & $0 / 71(0)$ \\
\hline
\end{tabular}

*Data not available for all patients. 
patients undergoing abortion $(n=63)$, sterilisation $(n=40)$, and from women practising barrier methods of contraception $(n=72)$. Sera were stored at $-20^{\circ} \mathrm{C}$ until tested by WIF and ELISA.

\section{SEROLOGY}

$C$ trachomatis $\mathrm{LGV} \mathrm{L} 1$ and $\mathrm{L} 2$ were chosen as test antigens because they show broad reactivity with a wide range of antibodies to $C$ trachomatis, and the $\alpha$-pili of $N$ gonorrhoeae P9-2 have immunodeterminants common to all gonococcal pili. Purification of these antigens has been described. ${ }^{1011}$

Sera were tested previously ${ }^{8}$ by an indirect whole inclusion fluorescence test using acetone fixed tissue culture cells infected with $C$ trachomatis $\mathrm{L} 2$ as antigen and antihuman gamma globulin fluorescein conjugate. $^{9}$

Conventional ELISA was performed using C trachomatis LGV L1 or Ngonorrhoeae P9-2 pili at protein concentrations of $1.0 \mu \mathrm{g}$ or $0.1 \mu \mathrm{g}$ per well, respectively, in carbonate-bicarbonate buffer $(\mathrm{pH}$ 9.6). Coating was carried out overnight at $4^{\circ} \mathrm{C}$ for chlamydiae and $37^{\circ} \mathrm{C}$ for pili. Tripling serum dilutions were made in $0.05 \mathrm{M}$ Tris $(\mathrm{pH} \mathrm{7.4)}$ containing $1 \% \mathrm{v} / \mathrm{v}$ normal goat serum, and the second antibody was a peroxidase conjugated, heavy chain specific rabbit antihuman IgG or IgA (DakoPats, Copenhagen). The substrate was $0 \cdot 15 \mathrm{M}$ tetramethylbenzidine in $0.15 \mathrm{M}$ sodium acetate $(\mathrm{pH} \mathrm{6})$, with $0.0003 \% \mathrm{v} / \mathrm{v} \mathrm{H}_{2} \mathrm{O}_{2}$ and the optical density $450 \mathrm{~nm}$ was determined with a Flow Multiskan spectrophotometer.

All serology was performed blind in each laboratory to avoid subjective error-ELISA in Southampton and WIF in Bristol.

\section{ANALYSIS OF DATA}

For ease of computation, the tripling serum dilutions (from $1 / 100$ ) were transformed to an integral $\log _{3}$ scale $(1,2,3$, etc.). After subtraction of the background the value of the absorbance was used to calculate the area under the titration curve using Simpson's rule by adaptation of a BASIC computer programme. ${ }^{12}$ Statistical analysis of the data was performed on a Honeywell 6080 mainframe computer using the software packages Minitab (Pennsylvania State University, University Park, Pennsylvania 16802, USA) and SPSS-X.

\section{Results}

EXPRESSION OF ELISA RESULTS USING AREA UNDER TITRATION CURVE

Fig 1 shows titration curves for two sera from this study. The sera have identical titres $(1 / 8100)$ using the conventional titration end point but are clearly different. One explanation is that the antibodies in serum A, are of higher avidity than those in serum B. Integration of the area under the titration curve reflects these differences, giving values of 19 and 6.9 , respectively.

Fig 2 shows the relation between area under the $\frac{\bar{O}}{\bar{D}}$ curve or titre end point and the maximum ELISA $\vec{\nabla}$ optical density achieved (in this case at the maximum $\cong$ serum concentration of 1/100). Fig 2a shows an excel- ळ lent curvilinear correlation between maximum optical $\overrightarrow{0}$ density on ELISA and the computed area under the $\vec{\overrightarrow{ }}$ ELISA curve $(r=0.95)$. Fig $2 b$ shows a similar but $\vec{\omega}$ weaker correlation between maximum optical density on ELISA and titre end point $(r=0.93)$. The wider dispersion of optical density at each titre end point compared with area under the curve reflects the fact that area under the curve is a continuous and not $\underset{\forall}{\mathcal{W}}$ discrete variable, and thus is a more accurate measurement than titre as it utilises data from all the titration wells.

DETERMINATION OF CHLAMYDIAL ANTIBODY BY ELISA AND WHOLE INCLUSION

FLUORESCENCE (WIF)

Sera were given a numerical code so that the clinical condition of the patient was unknown to the laboratories measuring chlamydial antibody. In Bristol antibodies were measured by immunofluorescence using cells infected with $C$ trachomatis $\mathrm{L} 2$ as antigen and in Southampton by ELISA using purified elementary bodies from $C$ trachomatis L1. Fig 3 shows the correlation between ELISA area under the curve and WIF titre. The results show good agreement between the two tests in the two laboratories, with a correlation coefficient $r=0.921$ assuming a linear correlation.

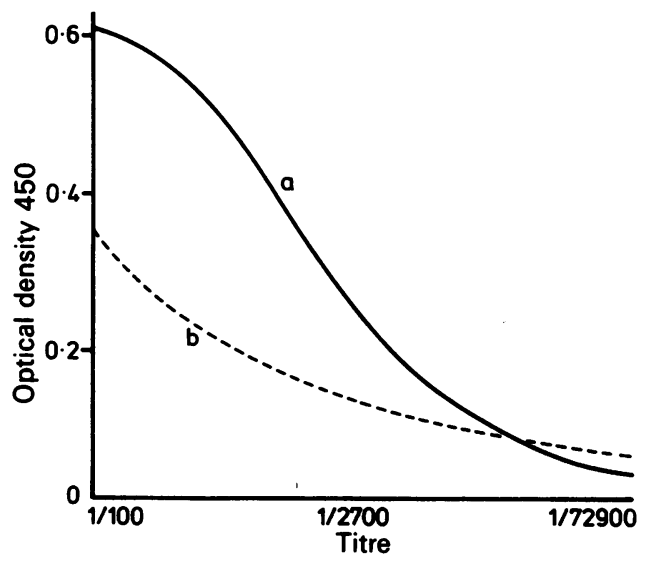

Fig 1 ELISA titration curve for two sera with identical titration end point of 1/8100. Integration of area under these titration curves reflects obvious difference between these sera. 


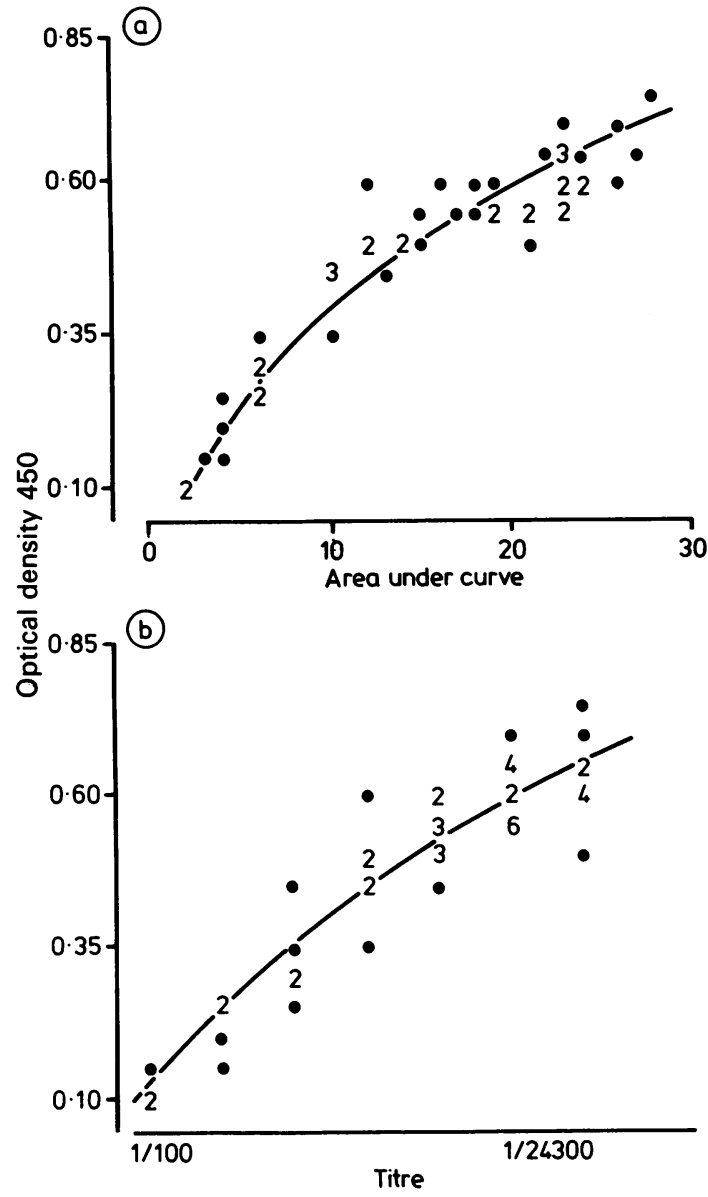

Fig 2a and 2b Scatter diagrams of antibody response to $C$ trachomatis LI measured by ELISA for infertile patients with tubal pathology. Graphs show relation between optical density on ELISA at 1/100 serum dilution and either (a) area under titration curve or (b) titre end point. Area under titration curve showed better correlation than titre end point with optical density. Thus optical density on ELISA of 1/100 serum dilution could be used as simple screen for chlamydial antibody.

\section{PREVALENCE OF ANTIBODY TO CHLAMYDIAE} AND GONOCOCCAL ANTIGENS

Fig 4 shows the percentage of patients with a given level of antibody to chlamydiae (measured by WIF or ELISA) and to gonococcal pili for each of the clinical categories examined. On the basis of these frequency distributions, sera having a WIF titre of $\geqslant 1 / 32$ or an ELISA area of $\geqslant 10$ were regarded as positive for chlamydial antibody. An ELISA area of $\geqslant 9$ was regarded as positive for antibody to gonococcal pili. Table 2 shows the prevalence of antibody in each of
Table 2 Prevalence of antibodies to chlamydiae and gonococcal pili in infertility and in controls

\begin{tabular}{llll}
\hline & \multicolumn{2}{l}{ No positive $(\%)$ by serological test: } \\
\cline { 2 - 5 } & $\begin{array}{l}\text { Chlamydia } \\
\text { PIF }\end{array}$ & $\begin{array}{l}\text { Chlamydia } \\
\text { ELIS } A\end{array}$ & $\begin{array}{l}\text { Gonococcal pili } \\
\text { ELISA }\end{array}$ \\
\hline Infertile with tubal & & & \\
$\quad$ pathology & $37 / 48(77)$ & $35 / 48(73)$ & $1 / 48 \quad(2)$ \\
Infertile with normal & & & \\
$\quad$ tubes & $26 / 77(34)$ & $26 / 77(34)$ & $2 / 77 \quad(3)$ \\
Barrier contraception & $17 / 72(24)$ & $18 / 72(25)$ & $3 / 72(4)$ \\
Pregnancy termination & $29 / 63(46)$ & $25 / 63(38)$ & $10 / 63(16)$ \\
Sterilisation & $19 / 40(48)$ & $15 / 40(38)$ & $2 / 40(5)$ \\
\hline
\end{tabular}

Antibody to purified gonococcal pili was measured by ELISA. Antibody to $C$ trachomatis was measured both by ELISA and by whole inclusion immunofluorescence (WIF).

the clinical categories. Excellent agreement was observed between the results of Conway et $a l^{8}$ using WIF and the ELISA results. Antibodies to $C$ trachomatis $\mathrm{Ll}$ were found in more of the infertile women with tubal pathology ( $73 \%$ by ELISA) than in any of the control groups ( $p<0.0001$, table 2$)$. No difference in antibody prevalence was found among the infertile women with normal tubes, the group undergoing sterilisation, and the women having abortions (34\%, 38\%, and $38 \%$, respectively). Twenty five percent of women using barrier methods of contraception had antibodies to chlamydiae. When the sera were tested by ELISA for antibodies to gonococcal pili very low prevalences $(2-5 \%)$ were found in all groups except those women having abortions, where $16 \%$ were positive for antibodies to pili $(p=0.03)$. Mean ELISA antibody (area under the curve) for infertile women with tubal pathology or with normal tubes, and fertile women seeking ster-

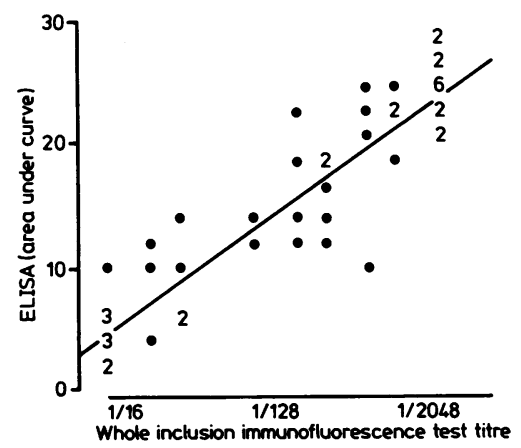

Fig 3 Sera from infertile women with tubal pathology were tested in Bristol for antibody to C trachomatis L2 by whole inclusion immunofluorescence (WIF) and independently in Southampton for antibody response to C trachomatis $L 1$ by ELISA. There was close agreement between results of both test procedures $(r=0.921)$. 
C trachomatis

Whole inclusion immunofluorescence test
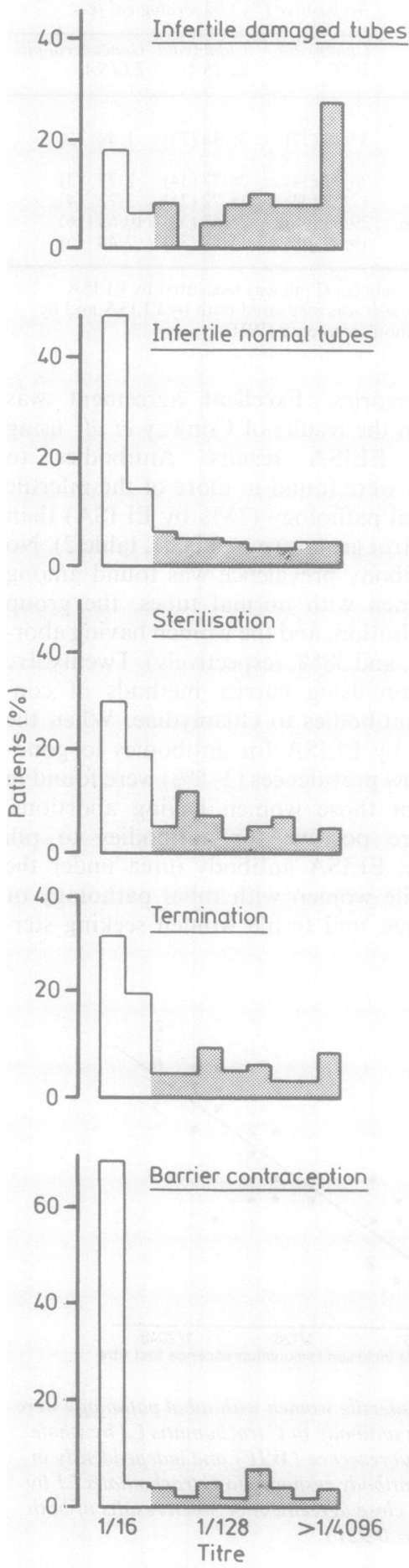

C trachomatis

ELISA
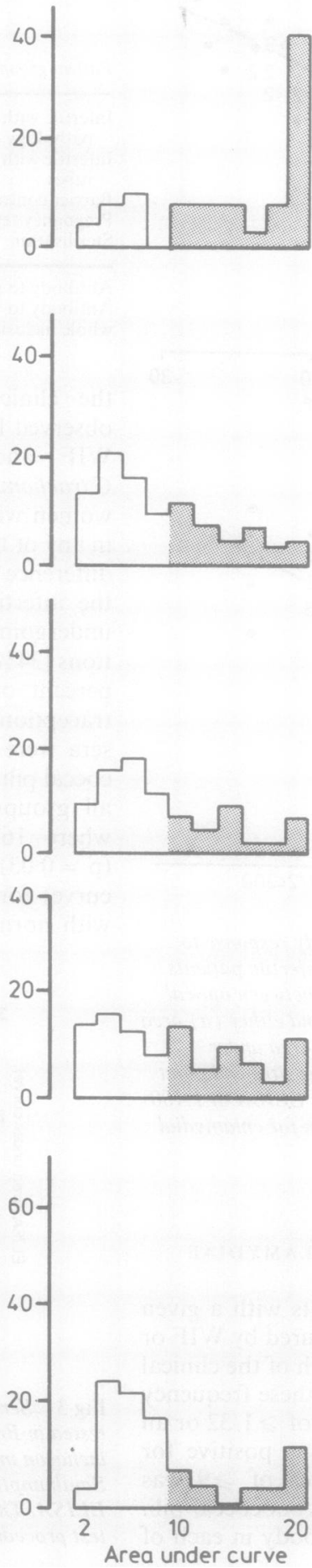

Ngonorrhoeae

ELISA
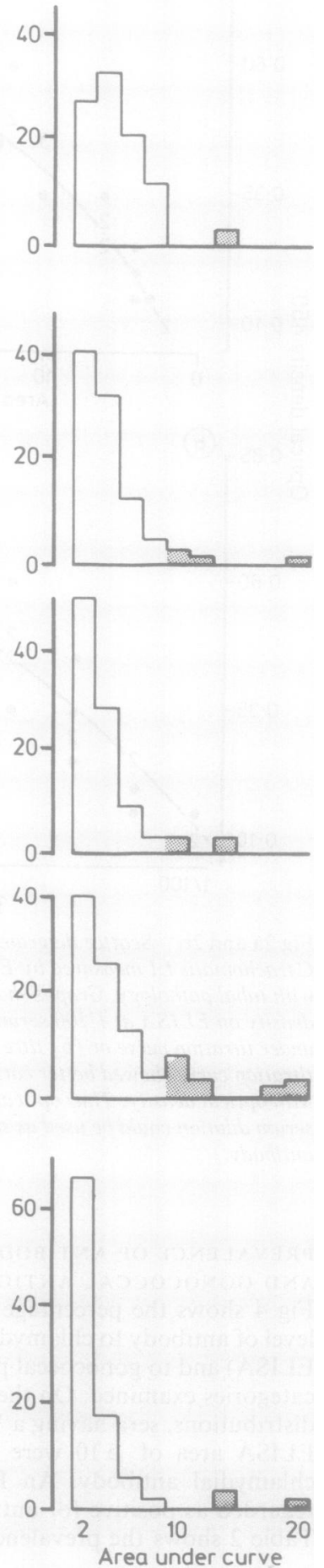

Fig 4 Frequency distributions of antibody response to purified gonococcal pili measured by ELISA and to C trachomatis serovars LI or L2 measured by ELISA, or whole inclusion immunofluorescence (WIF), respectively, in different clinical categories. ELISA results were expressed as area under titration curve. WIF results were expressed as titre end points. Antibody responses considered to be positive have been shaded. 
Table 3 Prevalence of antibody to $C$ trachomatis in infertile women with normal or damaged fallopian tubes

\begin{tabular}{|c|c|c|c|c|}
\hline \multirow[b]{3}{*}{ Type of infertility } & \multicolumn{4}{|c|}{ Infertility with: } \\
\hline & \multicolumn{2}{|c|}{ Tubal pathology } & \multicolumn{2}{|l|}{ Normal tubes } \\
\hline & Primary & Secondary & Primary & Secondary \\
\hline Mean length of infertility (years) & $5 \cdot 67$ & $3 \cdot 33$ & 3.52 & $2 \cdot 55$ \\
\hline No of patients* & $25 / 46(54 \%)$ & $21 / 46(46 \%)$ & $50 / 71(70 \%)$ & $21 / 71(30 \%)$ \\
\hline Prevalence of antibody to $C$ trachomatis $\mathrm{Ll}$ & $17 / 25(68 \%)$ & $16 / 21(76 \%)$ & $14 / 50(28 \%) \dagger$ & $9 / 21(43 \%) \dagger$ \\
\hline $\begin{array}{l}\text { Mean antibody response by ELISA in positive } \\
\text { patients (area under curve) }\end{array}$ & 18.9 & $20 \cdot 2$ & $14 \cdot 3$ & $13 \cdot 9$ \\
\hline
\end{tabular}

*Data not available for all patients.

+Not significant.

Primary infertility was defined as failure to conceive. Secondary infertility was infertility developing subsequent to an initial pregnancy. There was a significantly increased prevalence of chlamydial but not gonococcal antibody in infertile women with tubal pathology compared with that in infertile women with normal tubes.

ilisation, termination of pregnancy, or using barrier contraception was 19.6, 14.1, 16.4, 17.3, and 18.7, respectively indicating little difference in the level of antibody among positive sera in these groups.

Table 3 shows the prevalence of chlamydial antibody in sera from infertile women with either primary or secondary infertility. There was no significant difference between the prevalence of antibody to $C$ trachomatis in women with tubal pathology with either primary or secondary infertility. In infertile women with normal tubes, however, there was an increase in the prevalence of sera with chlamydial antibody in cases of secondary infertility. The mean antibody level, calculated from the area under the curve, was greater in positive sera from infertile women with tubal pathology than in positive sera from infertile women with normal tubes. There was no significant difference between level of antibody response according to whether these women were suffering from primary or secondary infertility.

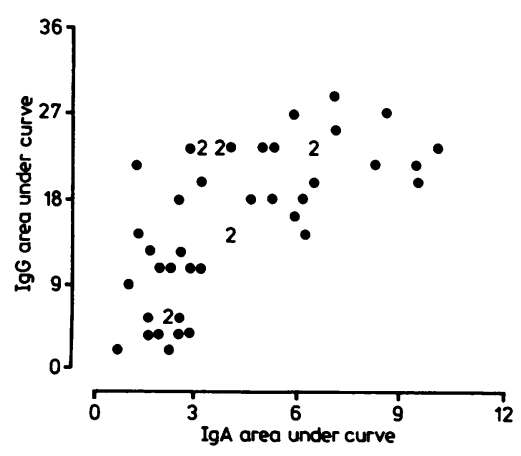

Fig 5 Relation between $\operatorname{Ig} G$ and $\operatorname{Ig} A$ antibody response by ELISA to C trachomatis for infertile patients with tubal pathology. Patients making IgG response generally also made IgA response.
PREDICTIVE VALUE OF SERUM IgA ANTIBODY

Sera from the 48 women with infertility associated with tubal pathology and from the 72 fertile women using barrier contraception were compared for the prevalence of serum IgA antibody to $C$ trachomatis. Twenty six of the infertile women $(54 \%)$ had $\operatorname{IgA}$ antibody compared with $22(31 \%)$ of the fertile controls. Fig 5 shows the correlation between ELISA area under the curve for circulating IgG and IgA antibody to $C$ trachomatis in infertile women with tubal pathology. In all cases high IgA antibody titres were associated with high IgG, but high IgG values were not necessarily associated with high IgA (fig 5).

\section{Discussion}

It is now well established that both $N$ gonorrhoeae and $C$ trachomatis cause salpingitis, which may lead to tubal damage and resulting infertility. In a recent worldwide survey tubal dysfunction was attributed as a cause of infertility in $11 \%$ of infertile European couples and in $49 \%$ of African couples. ${ }^{13}$ The risk of infertility following acute salpingitis is related to the number of episodes of salpingitis and the severity of the tubal inflammatory response observed at laparoscopy.

Studies in Scandinavia, France, Holland and the United Kingdom have documented an association between infertility with tubal pathology and the presence of circulating antibody to $C$ trachomatis. The results reported here confirm the findings of Conway $e t a l^{8}$ on the same group of patients, supporting the concept of $C$ trachomatis as a major cause of tubal damage and resultant infertility in the United Kingdom. Less information is available on the importance of gonococci in the aetiology of tubal infertility. Gonococcal infection results in persistent circulating IgG antibody to gonococcal pili. ${ }^{14}$ Pilus structure is hypervariable as a result of gene reassortment ${ }^{15}$; nevertheless, the human immune response includes 
antibody to a common immunodeterminant present on different gonococcal pili. ${ }^{16}$ Thus pili have been regarded as an excellent and specific antigen for the serological detection of gonococcal infection. ${ }^{14}$ The presence of persistent IgG antibody for both gonococci and chlamydiae as an indicator of past infection is of major importance in establishing the aetiology of tubal infertility, as, by the time infertility has become apparent, the acute genital tract infection will have usually resolved. The measurement of serum IgA titre against chlamydiae, however, did not improve the discrimination between sera from infertile and fertile women (fig 5), although it has been reported to be useful in the diagnosis of acute chlamydial infections, including salpingitis. ${ }^{17}$ IgM antibody to chlamydiae is rarely found in acute salpingitis. ${ }^{18}$

The prevalence of gonococcal antibody in infertile women and in women using barrier contraception or seeking sterilisation in this study was only $2-5 \%$. This low prevalence of antibody is consistent with a low cumulative rate of gonococcal infection in these women. Ten of 63 Bristol women (16\%) seeking termination of pregnancy, however, had antibody to gonococcal pili, suggesting that this group had a higher rate of gonococcal infection.

Overall, the data suggest that in the United Kingdom (Bristol) chlamydiae, rather than gonococci, are the most identified cause of tubal infertility. This finding is in agreement with data from Sweden ${ }^{3}$ and Denmark, ${ }^{1819}$ but is at variance with results from Holland. ${ }^{5}$ In that study gonococcal and chlamydial antibody was found in $60 \%$ and $21 \%$, respectively, of infertile women with tubal pathology but was absent from blood donors and children presumed not to have experienced gonococcal infection. Gonococcal antibody was found in $25 \%$ of infertile women with normal tubes, an unexpected result in view of the absence of antibody in control blood donor sera investigated by the same group. The reason for this difference in the aetiology of tubal infertility between Scandinavia and the United Kingdom on the one hand and Holland on the other is not clear.

In developing countries gonococci may be a more important cause of tubal infertility than in the United Kingdom. Using similar serological techniques in The Gambia, we observed that both gonococcal and chlamydial antibody were significantly associated with tubal infertility compared with that of matched fertile controls. ${ }^{7}$ The importance of gonococci in West Africa but not the United Kingdom in the aetiology of tubal fertility can be explained by the high level of carriage of both organisms in Gambian women, ${ }^{6}$ the four-fold increased proportion of overall infertility associated with infection in Africa, ${ }^{13}$ the increased contribution of chlamydiae to sexually transmitted disease in the United Kingdom, and the
Robertson, Ward, Conway, Caul
greater likelihood that the more florid gonococcal sal- $\frac{0}{\vec{*}}$ pingitis would be promptly treated in the United 을 Kingdom.

Our findings have shown an association between $\frac{\overrightarrow{5}}{0}$ infertility due to tubal obstruction and serological 등 evidence of a history of chlamydial infection. Clearly $\frac{\bar{\omega}}{\bar{\omega}}$. it would be desirable if serology could be used in con- $\vec{\Phi}$ junction with other tests to establish the presence of $\propto$ chlamydial infection when the patient presents with os pelvic inflammatory disease. This would permit the $\vec{O}$ use of antichlamydial chemotherapy prior to the $\vec{\overrightarrow{ }}$ development of infertility, might obviate unnecessary $\vec{\sim}$ and expensive investigation of the patient, and could $\overrightarrow{0}$ provide data on the success of local sexually transmitted disease clinic control measures. Technically, $\stackrel{t}{\circ}$ ELISA offers a simple method of screening large $\vec{\omega}$ numbers of patients for chlamydial antibody. Sera $y$ can be screened at a single dilution as shown by the $\mathrm{O}$ high correlation $(r=0.929$ for the tubal pathology group) of $\mathrm{OD}_{450} \mathrm{~nm}$ at a $1 / 100$ dilution of serum for $\vec{\nabla}$ IgG with the integrated titration curve. Moreover, the close agreement observed between the results of the ELISA and immunofluorescence tests in this study $\underset{\infty}{\infty}$ suggests that the tests were measuring similar anti-. bodies. By comparison with immunofluorescence, $\mathrm{O}$ ELISA is far less tedious for screening large numbers of sera, can be more objectively quantitated, and permits ready automation. The high titres of chlamydial (but not gonococcal) antibody by ELISA and WIF in $\stackrel{\unrhd}{\unrhd}$ control women using barrier contraception may $\overrightarrow{\overrightarrow{0}}$ result from previous infection with chlamydiae or $\frac{0}{3}$ might be due to antibody to other organisms cross reacting with chlamydial antigens. Essentially similar results were obtained irrespective of whether the ELISA was performed with whole $C$ trachomatis ele- ? mentary bodies or with purified outer membrane complex derived from them (data not shown).

In one study of acute salpingitis confirmed by laparoscopy, results for chlamydial antibody tests correlated well with the severity of tubal inflammation and duration of lower abdominal pain, but chlamy- $\rightarrow$ diae were isolated from less than $40 \%$ of patients. ${ }^{3}$ Thus failure to isolate chlamydiae from the lower gen- $N$ ital tract does not exclude these organisms as the $N$ causative agent. In these circumstances, given appropriate clinical indications, chlamydial antibody above $\omega$ a suitable cut off level might be a useful indicator of chlamydial infection. ${ }^{18}$ Commercial kits are available for measuring chlamydial antibodies by ELISA or WIF. Microimmunofluorescence has been widely used as a diagnostic test for type specific chlamydial $\frac{0}{0}$ antibody ${ }^{20}$ and might provide useful confirmation of $\frac{\vec{D}}{D}$ sera found positive by ELISA. Unfortunately, the $\stackrel{\odot}{\mathbb{\Phi}}$ microimmunofluorescence test is mainly restricted to $\stackrel{\mathbb{Q}}{2}$ research and reference laboratories. Moreover, the persistence of chlamydial antibodies following infec- 
tion and the possibility that infections with $C$ psittaci and some other organisms might give rise to antibodies cross reactive with $C$ trachomatis antigens means that caution is needed in interpreting the results of tests for chlamydial antibody on an individual patient. Improved methods of serological diagnosis for chlamydial pelvic inflammatory disease (PID) can be expected following detailed investigation of the antigenic specificity and persistence of human antibodies of different immunoglobulin class and subclass to chlamydiae. Meanwhile, although a diagnosis of chlamydial PID cannot be established with certainty by serology alone, a positive chlamydial antibody result by ELISA or immunofluorescence indicates the need for a more thorough investigation for chlamydial infection.

\section{References}

1 Moore DE, Spadoni LR, Foy HM, et al. Increased frequency of serum antibodies to Chlamydia trachomatis in infertility due to distal tubal disease. Lancet 1982;ii:574-7.

2 Mårdh P-A, Ripa T, Svensson L, Weström L. Chlamydia trachomatis infection in patients with acute salpingitis. $N$ Engl $J$ Med 1977;296:1377-9.

3 Mårdh P-A, Lind I, Svensson L, Weström L, Møller BR. Antibodies to Chlamydia trachomatis, Mycoplasma hominis and Neisseria gonorrhoeae in sera from patients with acute salpingitis. British Journal of Venereal Disease 1981;57:125-9.

4 Henry-Suchet J, Catalan F, Loffreda V, et al. Microbiology of specimens obtained by laparoscopy from controls and from patients with pelvic inflammatory disease or infertility with tubal obstruction: Chlamydia trachomatis and Ureaplasma urealyticum. Am J Obstet Gynecol 1980;138:1022-5.

5 Tjiam KH, Zeilmaker GH, Alberda ATh, et al. Prevalence of antibodies to Chlamydia trachomatis, Neisseria gonorrhoeae, and Mycoplasma hominis in infertile women. Genitourin Med 1985;61:175-8.

6 Mabey DCW, Lloyd-Evans NE, Conteh S, Forsey T. Sexually transmitted diseases among randomly selected antenatal clinic attenders in The Gambia. British Journal of Venereal Disease 1984;60:331-6.
7 Mabey DCW, Ogbaselassie G, Robertson JN, Heckels JE, Ward ME. Tubal infertility in The Gambia: Chlamydia and gonococcal serology in women with tubal occlusion compared with pregnant controls. Bull WHO 1985;63:1107-13.

8 Conway D, Glazener CMA, Caul EO, et al. Chlamydial serology in fertile and infertile women. Lancet 1984;i:191-3.

9 Richmond SJ, Caul EO. Fluorescent antibody studies in chlamydial infections. J Clin Microbiol 1975;1:345-52.

10 Salari SH, Ward ME. Polypeptide composition of Chlamydia trachomatis. J Gen Microbiol 1981;123:187-207.

11 Lambden PR. Biochemical composition of pili from variants of Neisseria gonorrhoeae. J Gen Microbiol 1982;128:2105-11.

12 Lee JD, Lee TD. Statistics and computer methods in BASIC. Wokingham: Van Nostrand Reinhold, 1982:151-8.

13 Cates W, Farley TMM, Rowe PJ. Worldwide patterns of infertility: is Africa different? Lancet 1985;2:596-8.

14 Oranje OP, Reimann K, van Eijk RVW, et al. Gonococcal serology. A comparison of three different tests. British Journal of Venereal Disease 1983;59:47-52.

15 Hagblom P, Segal E, Billyard E, So M. Intragenic recombination leads to pilus antigenic variation in Neisseria gonorrhoeae. Nature (Lond) 1985;315:156-8.

16 Buchanan TM. Antigenic heterogeneity of gonococcal pili. J Exp Med 1975;141:1470-5.

17 Cevenini R, Sarov I, Rumpaniesi F, et al. Serum specific IgA antibody to Chlamydia trachomatis in patients with chlamydial infections detected by ELISA and an immunofluorescence test. J Clin Pathol 1984;37:686-91.

18 Kristensen GB, Bollerup AC, Lind I, et al. Infections with Neisseria gonorrhoeae and Chlamydia trachomatis in women with acute salpingitis. Genitourin Med 1985;61:179-84.

19 Møller BR, Taylor-Robinson D, Furr PM, Toft B, Allen J. Serological evidence that chlamydiae and mycoplasmas are involved in infertility in women. $J$ Reprod Fert 1985;73:237-40.

20 Wang SP, Grayston TT, Kuo CC, Alexander ER, Holmes KK. Serodiagnosis of Chlamydia trachomatis infection with the micro-immunofluorescence test. In: Hobson D, Holmes KK, eds. Nongonococcal urethritis and related infections. Washington DC: American Society for Microbiology, 1977:237-48.

Requests for reprints to: Dr Janet Robertson, Faculty of Medicine, South Laboratory and Pathology Block, Southampton General Hospital, Tremona Road, Southampton SO9 4XY, England. 